\title{
Fever in pregnancy at term: fetal-maternal impact on maternity at the Talangai reference hospital in Brazzaville
}

\author{
Executive summary \\ Objectives: Determine the fetal-maternal impact of fever on term pregnancy in order to \\ control complications for better management of the mother-child relationship. \\ Patients and methods: This was a case-control study. Any pregnant woman with a fever \\ of $38.5^{\circ} \mathrm{C}$ or more was considered as a case, the non-febrile one as a control. Socio- \\ demographic and obstetrical variables; etiologies of fever; maternal and fetal complications \\ were studied. The results were analyzed using Stata 14 software. The logistic regression \\ model and Pearson's Chi-square test were applied.
}

Results: The frequency of fever and pregnancy is estimated at $1.48 \%$ of births.

The average age of the pregnant women was 28.32 years; the average parity was 1.79 years; $26.2 \%$ were married, $15 \%$ had a low level of education and $80.4 \%$ had an average socioeconomic level.

The etiologies of fever were: malaria $27 / 55$ (49\%); chorioamniotitis 12/55(21.8\%), occupational hyperthermia $13 / 55$ (23.6\%); acute pyelonephritis $2 / 55(3.6 \%)$ and pneumonia $1 / 55(1.8 \%)$. The difference between the two groups (cases and controls) is not significant in induction of labour 16/55 (29\%) cases versus 10/52 (19.2\%) controls; Complications of childbirth outcomes 20/55 (26.3\%) in cases versus 10/52 (19.2\%) in controls. On the other hand, the difference is significant in the number of cesarean sections $30 / 55(54.5 \%)$ of cases versus $9 / 52(17.3 \%)$ in controls; and stillbirths $22 / 55(40 \%)$ in cases versus $2 / 52(3.8 \%)$ in controls. According to the logistic regression, the age of the mother, the Apgar score, the socio-economic level and the quality of prenatal consultations are the only determining variables for the fetomaternal impact of fever on full-term pregnancy.

Conclusion: Fever in full-term pregnancy is harmful to the fetal-maternal development.

Keywords: fever, term pregnancy, becoming a maternal fetus, Brazzaville
Volume 10 Issue 6 - 2019

\author{
Jean Alfred Mbongo,' Herman Ndinga, ${ }^{2}$ \\ Gickelle Bitséné Mpika,' Roger Oyéré, ${ }^{2}$ \\ Clotaire Itoua,' Léon Hervé Iloki' \\ 'Department of Obstetrical Gynecology, University Hospital of \\ Brazzaville, Congo \\ ${ }^{2}$ Maternity Talangai Reference Hospital, Congo
}

Correspondence: Jean Alfred Mbongo, Department of Obstetrical Gynecology University Hospital of Brazzaville BP 32, Brazzaville, Congo, Tel +242 0553198/2, Email mbongoja@gmail.com

Received: November 21, 2019 | Published: December 27, 2019

\section{Introduction}

Fever turns a normal pregnancy into a high-risk pregnancy. It is a symptom that must be interpreted as a witness to the maternal organism's reaction to a pathological process, "fever is an enemy who wants you to be well". ${ }^{1}$

Fever in pregnant women is defined as a rectal temperature greater than or equal to $38.5^{\circ} \mathrm{C}$ at rest and in a normal environment. ${ }^{2}$ However, hyperthermia (temperature between 37.5 and $38.3^{\circ} \mathrm{C}$ ) is a physiological phenomenon resulting from the accumulation of heat in a context of maternal agitation, dehydration, environmental heat; it has no fetal or maternal repercussions. The distinction between hyperthermia and fever is not always easy; any thermal rise during labour must give rise to fears of infection and imposes the necessary preventive and curative measures. ${ }^{3}$

Fever with its effects on placental infusion would result in insufficient oxygen and nutrients being supplied to the fetus necessary for its metabolism, which would explain, for non-term pregnancies, the birth of hypotrophic children with low weight placentas. If in the West, in the face of a fever in full-term pregnancy, the diagnoses of pyelonephritis, chorioamniotitis and listeriosis should be mentioned. ${ }^{4}$ In Sub-Saharan African countries, malaria is the first thing to think about. ${ }^{5,6}$ Indeed, despite the efforts made in the fight against malaria, this disease still ranks high on the list of major tropical endemics.

In Congo Brazzaville, congenital malaria is a reality, its frequency has been estimated at $14.7 \%$ of malaria mothers at Brazzaville University Hospital and the form encountered is congenital malaria infection. ${ }^{7}$ Fever in term pregnancy is associated with a number of complications that would be important to control for better management of the mother-child relationship.

Thus we wanted to determine the fetal-maternal impact of fever on full-term pregnancy.

\section{Patients and methods}

This was a case control study that took place from January 5 to July 5, 2019, in the Maternity Hospital of the Talangai Reference Hospital in Brazzaville.

We included all pregnant women in labour or not and whose term was between 37 and 40 weeks. They were divided into two groups: 


\section{a. The case group: those with fever}

\section{b. The control group: those without fever}

Excluded: Pregnant women with additional pathology, multiple pregnancies, antenatal deaths; pregnant women on antibiotic therapy and/or antimalarial drugs who presented an infectious syndrome at the end of pregnancy.

The data collection was of a probabilistic type.

The variables studied were in the two socio-demographic groups (age, marital status, level of education, socio-economic level, occupation); obstetrical (parity, quality of prenatal contacts, mode of entry into labour, mode of delivery, maternal complications up to 42 days and fetal complications up to 7 days). For the "cases", the cause of the fever was investigated.

The analysis of the results was done on the Stata 14 software. All the variables studied were qualitative. Before estimating the logistic regression model, a Pearson's Chi-square test was previously performed to examine the relationship between the variable of interest (fetal fate) and the other explanatory variables. We have grouped together certain variable modalities in order to comply with the condition of application of the test, which stipulates that the theoretical number of employees must be greater than or equal to 5. The estimation of the logistic regression allowed us to obtain the Odds-ratio. In all cases, the analysis of the estimates is set at the 5\% significance threshold.

\section{Results}

During the study period 3700 deliveries were delivered, 107 pregnant women met the inclusion criteria, including 55 cases and 52 controls. The frequency of fever and pregnancy is estimated at $1.48 \%$ of births. The average age of pregnant women was 28.32 years (extremes 15 to 42 ); the average parity was 1.79 (extremes 0 to 5); $15 \%$ of low school level. The Paucipars represented $82 \%$ of the study population. The other socio-demographic variables are represented in Table 1.
The etiologies of fever were: malaria 27/55 (49\%); chorioamniotitis 12/55 (21.8\%), Occupational hyperthermia 13/55 (23.6\%); Acute Pyelonephritis 2 / $55(3.6 \%)$ and pneumonia 1/55 (1.8\%).

The assessment of the labour process and complications of childbirth complications showed no significant difference between cases and controls, the practice of cesarean section being more important in cases than in controls (Table 2).

Stillbirths were higher in cases than in controls, good Apgar scores higher in controls than in cases, the difference was significant (Table $3)$. The number of poor Apgar scores is higher in controls than in cases, the difference is not significant (Table 4).

The Dependency relationship between fetal-maternal impact and study population variables allowed us to represent the following information in Table 5:

i. Children born to mothers over 25 are 11 times more likely to survive than those born to mothers under 25. Similarly, children born to women of average socio-economic status are more likely to survive birth than those born to women of low socio-economic status. In other words, the risk of death for a child therefore decreases as the mother's socio-economic level increases.

ii. The probability of survival for a newborn baby was related to the quality of prenatal contact. Indeed, newborns of a mother with poor prenatal contact are less likely $(0.21)$ to survive than children born to a mother with good prenatal contact.

iii. At the 5\% threshold, the newborn not admitted to neonatology is 5 times more likely to survive than a newborn transferred to neonatology.

According to the logistic regression (Table 6), the variables as mode of delivery, the consequences of childbirth for the mother, the mother's marital status and parity have no influence on the fate of the newborn at the 5\% threshold. On the other hand, the age of the mother, the Apgar rating, the socio-economic level and the quality of prenatal consultations are the only variables that determine the impact of fetomaternal fever on term pregnancy.

Table I Socio-economic data

\begin{tabular}{|c|c|c|c|c|c|c|}
\hline & \multicolumn{2}{|c|}{ Cases } & \multicolumn{2}{|c|}{ Witnesses } & \multicolumn{2}{|l|}{ Total } \\
\hline & $n=55$ & $\%$ & $n=52$ & $\%$ & $N=107$ & $\%$ \\
\hline \multicolumn{7}{|l|}{ Marital status } \\
\hline Married & 13 & 23,6 & 15 & 28,8 & 28 & 26,2 \\
\hline Single & 7 & 12,7 & 10 & 19,2 & 17 & 15,9 \\
\hline Common-law union & 35 & 63,6 & 27 & 51,9 & 62 & 57,9 \\
\hline \multicolumn{7}{|c|}{ Socio-economic level } \\
\hline Bottom & 12 & 21,8 & 4 & 7,7 & 16 & 15 \\
\hline Medium & 39 & 70,9 & 47 & 90,4 & 86 & 80,4 \\
\hline High & 4 & 7,3 & 1 & 1,9 & 5 & 4,7 \\
\hline \multicolumn{7}{|l|}{ Prenatal contact } \\
\hline Good quality & 29 & 52,7 & 40 & 76,9 & 69 & 64,5 \\
\hline Poor quality & 26 & 47,3 & 12 & 23,1 & 38 & 35,5 \\
\hline
\end{tabular}


Table 2 Maternal complications

\begin{tabular}{|c|c|c|c|c|c|c|}
\hline & \multicolumn{2}{|l|}{ Cases } & \multicolumn{2}{|c|}{ Witnesses } & \multicolumn{2}{|l|}{ Total } \\
\hline & $n=55$ & $\%$ & $n=52$ & $\%$ & $N=107$ & $\%$ \\
\hline \multicolumn{7}{|l|}{ Labour and Delivery } \\
\hline Triggering & 16 & 29,1 & 10 & 19,2 & 26 & 24,2 \\
\hline Quick work & 4 & 7,3 & 4 & 7,7 & 8 & 7,4 \\
\hline Dynamic dystocia & 22 & 40 & 20 & 42,3 & 42 & 39,2 \\
\hline \multicolumn{7}{|l|}{ Mode of delivery } \\
\hline Caesarean section & 30 & 54,5 & 9 & 17,3 & 39 & 36,4 \\
\hline Low track with episiotomy & 5 & 9,1 & 1 & 1,9 & 6 & 5,6 \\
\hline Low track & 20 & 36,4 & 42 & 80,8 & 62 & 57,9 \\
\hline \multicolumn{7}{|c|}{ Complications of layer sequences } \\
\hline Anemia & 12 & 21,8 & 5 & 9,6 & 17 & 15,8 \\
\hline Endometritis & 6 & 10,9 & 6 & 11,5 & 12 & 11,2 \\
\hline
\end{tabular}

Table 3 States of children at birth

\begin{tabular}{lllllll}
\hline & Cases & \multicolumn{3}{c}{ Witnesses } & \multicolumn{2}{c}{ Total } \\
\cline { 2 - 7 } & $\mathbf{n}=\mathbf{5 5}$ & $\%$ & $\mathbf{N}=\mathbf{5 2}$ & $\%$ & $\mathbf{n}=1 \mathbf{0 7}$ & $\%$ \\
\hline Apgar=0 & 22 & 40 & 2 & 3,8 & 24 & 22,4 \\
Apgar I to 4 & 8 & 14,5 & 11 & 21,2 & 19 & 17,8 \\
Apgar 5 to 6 & 12 & 21,8 & 15 & 28,8 & 27 & 25,2 \\
Apgar $\geq 7$ & 13 & 23,6 & 24 & 46,2 & 37 & 34,6 \\
\hline
\end{tabular}

Apgar $=0$ exact test Fisher's $=0.000$ (significant)

Good Apgar scores are more common in controls

Table 4 Fetal complications

\begin{tabular}{lllllll}
\hline & Cases & \multicolumn{3}{c}{ Witnesses } & \multicolumn{2}{c}{ Total } \\
\cline { 2 - 7 } & $\mathbf{N}=\mathbf{5 5}$ & $\%$ & $\mathbf{N}=\mathbf{5 2}$ & $\%$ & $\mathbf{n = 1 0 7}$ & $\%$ \\
\hline Bad apgar & 20 & 36,3 & 26 & 50 & 46 & 42,9 \\
Transfer to neonatology & 8 & 14,5 & 11 & 21,2 & 19 & 17,7 \\
Fetal death & 22 & 40 & 2 & 3,8 & 24 & 22,4 \\
\hline
\end{tabular}

Poor Apgar: Pearson chi2 $(\mathrm{I})=0.6583 \mathrm{Pr}=0.417$ (not significant)

Citation: Mbongo JA, Ndinga H, Mpika GB, et al. Fever in pregnancy at term: fetal-maternal impact on maternity at the Talangai reference hospital in Brazzaville. Obstet Gynecol Int J. 2019;10(6):430-435. DOI: I0.15406/ogij.2019.10.00479 
Table 5 Dependency relationship between fetal-maternal impact and study population variables

\begin{tabular}{lll}
\hline & Chi2 statistics & Probability of the test (p-value) \\
\hline Parity & 22,706 & 0,132 \\
Apgar rating & 8.5928 & 0.014 \\
Age of the pregnant woman & 174,033 & $0,000^{*}$ \\
Socio-economic level & 104,554 & $0,005^{*}$ \\
Suites of complicated layers & 60,621 & $0,014^{*}$ \\
Maternal fever & 0,0265 & 0,871 \\
Prenatal contact & 112,341 & $0,00 I^{*}$ \\
Mode of delivery & 23,066 & 0,316 \\
Marital status & 51,458 & 0,074 \\
Type of complication of the mother & 0.6312 & 0.729 \\
Fever etiologies & 1.6664 & 0.644 \\
Neonatology Transfer & 75,766 & $0,006^{*}$ \\
\hline
\end{tabular}

*Significant at the $5 \%$ threshold

Table 6 Logistic regression results on study variables

\begin{tabular}{|c|c|c|c|c|c|c|}
\hline $\begin{array}{l}\text { Resonance } \\
\text { foeto-motherly }\end{array}$ & Odds Ratio & Std. Err. & $\mathbf{z}$ & $\mathbf{P}>\mathbf{Z}$ & 95\% Conf. & Interval] \\
\hline \multicolumn{7}{|l|}{ Febrile state } \\
\hline Witnesses & 0.2326706 & 0.3654691 & -0.93 & 0.353 & 0.0107081 & 5.055598 \\
\hline \multicolumn{7}{|l|}{ Apgar } \\
\hline$[1 ; 4]$ & 12.43002 & 19.88336 & 1.58 & 0.115 & 0.5405918 & 285.8079 \\
\hline$[5 ; 6]$ & 8.173745 & 10.73847 & 1.6 & 0.11 & 0.6224902 & 107.3272 \\
\hline$[7 ; 10]$ & $|4.835| 6$ & 19.90429 & 2.01 & 0.044 & 1.06964 & 205.7533 \\
\hline \multicolumn{7}{|l|}{ Etiology } \\
\hline Hyperthermia of_work & 0.5835237 & 0.8716002 & -0.36 & 0.718 & 0.0312343 & 10.90147 \\
\hline Chorio-_amniotite & 0.8784235 & I.75729| & -0.06 & 0.948 & 0.0174129 & 44.31365 \\
\hline Malaria & 0.46384 & 0.8074663 & -0.44 & 0.659 & 0.0152958 & |4.06582 \\
\hline \multicolumn{7}{|l|}{ Age group } \\
\hline More than 25 years old & 11.85145 & 7.836265 & 3.74 & $0.000 *$ & 3.243026 & 43.3104 \\
\hline \multicolumn{7}{|l|}{ Socio-economic level } \\
\hline Medium & II.0872 & 9.195292 & 2.9 & $0.004 *$ & 2.18207 & 56.3346 \\
\hline \multicolumn{7}{|l|}{ Layer_suites } \\
\hline Simple & 0.9599921 & 0.7042114 & -0.06 & 0.956 & 0.227961 & 4.04273 \\
\hline
\end{tabular}

Citation: Mbongo JA, Ndinga H, Mpika GB, et al. Fever in pregnancy at term: fetal-maternal impact on maternity at the Talangai reference hospital in Brazzaville. Obstet Gynecol Int J. 2019;10(6):430-435. DOI: 10.15406/ogij.2019.10.00479 
Table continue

\begin{tabular}{|c|c|c|c|c|c|c|}
\hline $\begin{array}{l}\text { Resonance } \\
\text { foeto-motherly }\end{array}$ & Odds Ratio & Std. Err. & $\mathbf{z}$ & $\mathbf{P}>\mathbf{Z}$ & 95\% Conf. & Interval] \\
\hline \multicolumn{7}{|c|}{ Normal state of the child } \\
\hline & 0.9119994 & 0.799232 & -0.11 & 0.916 & 0.1636978 & 5.080965 \\
\hline \multicolumn{7}{|l|}{ Prenatal contact } \\
\hline Poor quality & 0.2148699 & 0.1307915 & -2.53 & $0.012^{*}$ & 0.0651701 & 0.7084394 \\
\hline \multicolumn{7}{|l|}{ Childbirth } \\
\hline By Caesarean section & $0.4638 I 44$ & 0.3140336 & -1.13 & 0.256 & 0.1230335 & I.748497 \\
\hline \multicolumn{7}{|l|}{ Marital status } \\
\hline Single & 0.4436289 & 0.4259338 & -0.85 & 0.397 & 0.0675725 & 2.912524 \\
\hline Common-law union & 0.5074428 & 0.3733034 & -0.92 & 0.356 & 0.120004 & 2.145748 \\
\hline \multicolumn{7}{|c|}{ Transfer_neonatology } \\
\hline No & 5.428889 & 4.287708 & 2.14 & $0.032^{*}$ & 1.154613 & 25.52616 \\
\hline _cons & 0.023202 & 0.0560079 & -1.56 & 0.119 & 0.0002045 & 2.63184 \\
\hline
\end{tabular}

Logistic regression Number of obs $=107$ LR chi2 $(16)=56.92$

Log likelihood $=-43.215823$ Nickname R2 $=0.397 \mid$ Prob $>$ chi2 $=0.0000$

*Significant at only $5 \%$

\section{Discussion}

The frequency of fever in term pregnancy has been estimated at $1.48 \%$ of births, which is consistent with data in the literature reporting frequencies ranging from 1 to $10.1 \%$ of births, depending on the country, and sampling. ${ }^{3,5,8,9}$ The etiologies of fever are dominated by malaria in almost half of all cases. Indeed, in sub-Saharan Africa, when faced with a fever during pregnancy, one must first think of malaria, ${ }^{1,5,6}$ while in the West an unexplained fever during pregnancy must be considered and treated as a listeria infection until proven otherwise, if the fever persists without etiological orientation after 72 hours, the opinion of an infectiologist is required. The primacy of the etiologies of fever and term pregnancy in the West is therefore attributed to bacterial infections. ${ }^{10-12}$ This disparity can be explained by the fact that not only Sub-Saharan Africa is the malaria endemic area, but also by the fact that febrile conditions related to listeriosis and rickettsiosis cannot be identified due to deficient technical platforms.

The determining variables in the fetal-maternal impact of the association between fever and pregnancy at term were the age of the mothers, the socio-economic level, the quality of prenatal surveillance and the child's adaptation to extrauterine life. This can be explained by the fact that at an age of 25 years and over, the pregnant woman is socially responsible for her, and is able to do either a small job or be in a home where she is cared for by her partner. Thus, the socio-economic level at this age group can improve, also promoting the quality of prenatal surveillance. Malaria being the first etiology implicated in the proud association and long-term pregnancy in our geographical area, the low school level and low standard of living, interfere with the understanding of malaria transmission and prevention mechanisms. For some authors, ${ }^{8}$ while poverty can be questioned, age and parity do not significantly influence the feverish states associated with malaria in pregnant women. As chorioamniotitis is the second most common cause of fever in pregnancy, it may be the consequence of malaria. Indeed, the latter, by releasing pyrogenic substances at the systemic level, inducing uterine contractions, can promote the rupture of the membranes thus making the bed of the chorioamniotitis.

Labour hyperthermia occurring with a fairly high frequency $(23.6 \%)$ may be related to our difficult working conditions (lack of air conditioning in delivery rooms). Hyperthermia is a physiological phenomenon resulting from the accumulation of heat in a context of maternal agitation, dehydration, environmental heat, it has no fetal or maternal effects. ${ }^{11}$

Fever in the term pregnant woman did not significantly induce more labour induction, complications of post-partum complications, but it did promote more cesarean deliveries. Poor Apgar scores appear more in controls than in cases; however the difference is not significant. Malaria being the main cause of fever in our environment, we did not observe "lightning work", as described by some authors. ${ }^{1}$ However, our work confirms the claims in the literature that the rate of cesarean section is higher in fever than in controls due to acute fetal asphyxia and dystocia. ${ }^{3}$ The aftermath of childbirth was not particularly worrying in cases of fever than in controls. For some authors, fever is thought to increase the rate of endometritis and the length of hospitalization related to cesarean section. ${ }^{3}$ Indeed, the harmful nature of fever on term pregnancy has already been reported in the literature. ${ }^{12,13}$ For young pregnancies, the consequences of malaria with the resulting fever are worrying due to the number of anaemia, low birth weight, and premature births. ${ }^{14}$ If the mother has several means to regulate her temperature in the event of hyperthermia (undressing, hypersudation, hyperventilation, room cooling), the foetus has only two means: the "tissue" means through its skin surface 
via amniotic fluid and maternal tissues; the "vascular" means through placental exchanges. ${ }^{15}$ However, any increase in maternal temperature leads to an increase in fetal temperature of $0.5^{\circ} \mathrm{C}$ above maternal temperature, which results in fetal tachycardia and a risk of sudden fetal death. ${ }^{16}$ This may explain the high rate of stillbirths $(22 / 55$ or $40 \%$ ) among children born to febrile mothers, while it is low in the case of non-febrile parturient women (2/52 or $3.8 \%)$.Unlike in the West, where the severity of fever for the mother has been less since the development of antibiotic therapy, ${ }^{17}$ in sub-Saharan Africa, despite the proliferation of anti-malarial drugs and progress in antibiotic therapy, maternal complications of fever in term pregnancy are significantly greater in pregnant febrile than in non-febrile gestation.

\section{Limit of the study}

The limited number of pregnant women could be a bias in this study, but the statistical tests show that the exploration of the data leads to the rather interesting result, it is necessary to continue the studies with a larger sample.

\section{Conclusion}

On term pregnancy, fever did not significantly increase the number of labour induction, its acceleration, or the frequency of complications from childbirth. However, it increases the number of cesarean sections and stillbirths.

\section{Acknowledgments}

None.

\section{Funding}

None.

\section{Conflicts of interest}

The authors declare there are no conflicts of interest.

\section{References}

1. Correa P, Bah MD, Diallo S, et al. Malaria and pregnancy. Obstetrical Gynecology and Reproductive Biology. 1982;11(1):2-42.

2. Viola polona. Fièvre pendant la grossesse: des conséquences à long terme pour l'enfant. EMC. 2009;8(77):6.
3. Berland M, Communal PH, Pinaton B, et al. Fever during childbirth. Excerpt from the updates in Gynecology and Obstetrics 1996. CNGOF 25th National Days. Paris; 1996.

4. French-speaking virtual medical university. Main complications of pregnancy. 2010-2011 CNGOF.

5. Moussa Fatogoma B. The association fever and pregnancy in the Gyneco-Obstetrics department of the reference Health Centre of Commune V of the Bamako district. PhD Thesis Doctorate in Medicine University of Bamako; 2008.

6. Chenge M, Kalenga MK, Kakoma. Febrile states among pregnant women in Lubumbashi (DRC). Revue Française Gynécologie Obstétrique. 1998;6(93):475-480.

7. Mbongo JA, Ekouya Bowassa G, Koulimaya Gombet CE, et al. Congenital malaria at the Brazzaville Hospital and University Centre. An epidemiological study of 90 cases. Health Science Disease. 2015;4(16):1-5.

8. Togo A. Study of the association Pyelonephritis and pregnancy in the gynaeco-obstetrics department of the Point G National Hospital on 61 cases. Thesis in Medicine Bamako; 1993.

9. Petrova A, Demissié K, Rhods GG, et al. Association of maternel faver during labor with neonatal and infant morbidity and mortality. The américan College of Obstetricians and gynecologists. 2001;1(98):20 27.

10. Grard B, Refusal M. Main complications of pregnancy. Part 5-fever and pregnancy. The Practitioner's Review. 2007;57:665-669.

11. Girard B, Dufus M. Fever and pregnancy. Journal of Gynaecology, Obstetrics and Reproductive Biology. 2008;HS1(37):41-48.

12. Benedicte G, Dreyfus M. Main complications of pregnancy. Part 5-fever and pregnancy. Practitioner's Review. 2007;57:665-669.

13. Group of gynaecologists Obstetricians of French languages from Belgium. Perinat GGOLFB 2017 Protocol.

14. Kamissoko Mamady M. Prevalence of malaria in pregnancy in Bamako District. PhD Thesis Doctorate in Medicine Bamako University; 2015.

15. Reviron S. Fever during labour. Medical Thesis. University of FranchCourt; 2005.

16. Bandet JH, Ronayette D. Newborn mother's baby febrile infection. 2nd ed. Practical Obstetrics Maloine; 1990:427-437.

17. Lansac J, Munet H, Oury JF. Fever at the beginning of labour: What to do. Birth practice; 2006:263-269. 